\title{
Elementos formadores do capital intelectual no contexto das pequenas e médias empresas
}

\author{
Vanessa Aparecida Scantamburlo \\ Diander Saracho Delgado \\ Rafael Todescato Cavalheiro \\ Andréia Maria Kremer \\ Bacharel em Ciências Contábeis. Faculdade de Educação, Tecnologia e Administração de Caarapó \\ (FETAC) - Brasil. nessa.cpo@hotmail.com \\ Bacharel em Ciências Contábeis. Faculdade de Educação, Tecnologia e Administração de Caarapó \\ (FETAC) - Brasil. diander d@hotmail.com \\ Mestre em Agronegócios. Faculdade de Educação, Tecnologia e Administração de Caarapó (FETAC) \\ - Brasil. rafaeltodescato@hotmail.com \\ Doutoranda em Administração. Faculdade de Educação, Tecnologia e Administração de Caarapó \\ (FETAC) - Brasil. andreiakremer@hotmail.com
}

\section{RESUMO}

Devido aos avanços nas discussões sobre o Capital Intelectual e da importância econômica e social das Pequenas e Médias Empresas (PMEs) para o Brasil, este estudo teve por objetivo identificar a presença dos elementos formadores do Capital Intelectual $(\mathrm{Cl})$ no contexto das PMEs. Para tanto, realizou-se um estudo multicaso com aplicação de questionário adaptado de Bontis (1998) e entrevistas com abordagem qualitativa e quantitativa. Para análise da presença dos elementos formadores do $\mathrm{Cl}$, utilizou-se como base o estudo de Gimenes et al. (2016). Os resultados revelam uma forte presença dos elementos Capital Relacional, Capital Estrutural e Capital Humano, tanto na empresa Alfa (pequena empresa) quanto na empresa Beta (média empresa), demonstrando que os elementos formadores do $\mathrm{Cl}$ estão presentes no contexto das PMEs. As evidências de conteúdo permitem inferir, que em ambas as empresas, os gestores reconhecem a existência do $\mathrm{Cl}$ e acreditam na sua importância, porém ainda não possuem medidas que possibilitam mensurar 0 valor desses ativos intangíveis. Verificou-se também o desejo dos gestores de obterem relatórios que evidenciem 0 grau de contribuição dos elementos formadores do $\mathrm{Cl}$ na maximização do valor da empresa, de modo a subsidiar a tomada de decisão.

Palavras-chave: Capital Intelectual. Capital Humano. Capital Relacional. Capital Estrutural.

\section{Forming elements of Intellectual Capital in the context of small and medium-sized enterprises}

\section{ABSTRACT}

Due to advances in the discussions about Intellectual Capital and the economic and social importance of Small and Medium Enterprises (SMEs) for Brazil, this study aimed to identify the presence of the Intellectual Capital (CI) forming elements in the context of SMEs. A multi-sound study was carried out using a questionnaire adapted from Bontis (1998) and interviews with a qualitative and quantitative approach. For the analysis of the presence of the IC forming elements, the study of Gimenes et al. (2016) was the basis. The results reveal a strong presence of the Relational Capital, Structural Capital and Human Capital elements, both in the company Alpha (small company) and in the company Beta (medium company), demonstrating that the elements forming the IC are present in the context of SMEs. The content of evidence allows us to infer that in both companies, managers recognize the existence of the IC and believe in its importance, but they, so far, do not have the means that make it possible to measure the value of these intangible assets. There was also the desire of the managers to obtain reports that show the degree of contribution of the elements forming the IC in the maximization of the value of the company, in order to provide subsidies to the decision-making process.

Keywords: Intellectual capital. Human capital. Relational Capital. Structural Capital. 


\section{INTRODUÇÃO}

O conceito de Capital Intelectual $(\mathrm{Cl})$ vem sendo discutido há anos e tem se tornado cada vez mais presente no contexto empresarial, principalmente pelo crescimento e difusão das operações multinacionais, aumento da competição mundial e da internacionalização do mercado de capitais. 0 forte avanço da contribuição humana nas atividades empresariais, as inovações tecnológicas e o estreitamento entre clientes, fornecedores e colaboradores resultam em uma fonte significativa de valor para as organizações. Dentre as várias linhas de estudos referentes ao conhecimento nas organizações, uma delas se volta para o $\mathrm{Cl}$.

$\mathrm{O} \mathrm{Cl}$ pode ser considerado como o conhecimento que pode ser convertido em valor, tais como ideias, inovações, conhecimentos gerais, projetos, programas computacionais, processos e publicações (EDVINSSON; SULLIVAN, 1996). 0 Cl engloba um conjunto de ativos imateriais, invisíveis ou intangíveis, que não aparece nos balanços, porém são fontes de inovação (AGOSTINI; NOSELLA; FILIPPINI, 2017) e de criação de valor (SANG; DENNIS, 2014). O Cl pode ser classificado em Capital Humano (CH), Capital Estrutural (CE) e Capital de Clientes (CC) (STEWART, 1998).

O CH está diretamente relacionado às pessoas e representa a capacidade, conhecimento, habilidade e experiência individual dos colaboradores (GUBIANI; MORALES; SELIG, 2013). 0 CEé representado pelo capital organizacional, capital de inovação e capital de processos, ou seja, a estrutura física e tecnológica, os sistemas e processos técnicos e administrativos, a cultura, valores e ambiente organizacional, os conceitos, modelos e rotinas, as marcas, patentes e os sistemas de informática, que suportam a operação efetiva da organização (BONTISA et al., 1999). Já o CC, também classificado por Edvinsson e Malone (1998) como Capital Relacional, representa a estrutura de relacionamento da organização, com as quais a empresa faz negócios e gerencia seus contatos com parceiros estratégicos, fornecedores, clientes e outros grupos de interesse para as organizações (STEWART, 1998; ROOS; ROOS, 1997).

$\mathrm{O}$ valor dos elementos do $\mathrm{Cl}$ geralmente não são evidenciados de forma analítica nos balanços contábeis devido a sua natureza intangível. Ignorar ou desconhecer essas informações, pode interferir diretamente na tomada de decisão e, consequentemente, na estratégia das organizações (VARGAS et al., 2008).

Diversos estudos sobre o $\mathrm{Cl}$ foram realizados no Brasil abrangendo as dificuldades encontradas no processo de mensuração (REIS, 2005), a evidenciação e disclosure (JOIA, 2001; ENSSLIN et al., 2008; CRUZ; ALVES, 2013) e a elaboração de relatórios de divulgação (OLIVEIRA; BEUREN, 2003; ANTUNES, 2006). A identificação de elementos formadores do $\mathrm{Cl}$ também tem sido agenda de pesquisa no contexto científico nacional, como pode ser observado nos estudos de Colauto et al. (2011), Silva, Nagano e Merlo (2008) e Santos et al. (2016), porém poucos trabalhos têm se debruçado sobre a identificação de elementos formadores do Cl no contexto das pequenas e médias empresas (PMEs). No estudo realizado por Dorce, Cavalheiro e Gimenes (2017), observa-se que o único trabalho que abordou as PMEs foi o de Carlos Filho et al. (2014) que verificou a percepção dos micro e pequenos empreendedores que possuem familiaridade com os termos ativos intangíveis e/ou $\mathrm{Cl}$ e a importância atribuída aos seus elementos.

Considerando a importância e relevância do $\mathrm{Cl}$ para o desempenho organizacional e da importância econômica e social das PMEs, o presente estudo tem por objetivo identificar a presença dos elementos formadores do $\mathrm{Cl}$ no contexto das PMEs. $\mathrm{O}$ estudo aqui proposto visa contribuir para o preenchimento dessa lacuna na produção científica nacional, bem como para ressaltar a importância estratégica do $\mathrm{Cl}$ para as organizações de pequeno e médio porte, haja vista que o $\mathrm{Cl}$ impacta significativamente no desempenho e na capacidade de inovação das PMEs (SANG; DENNIS, 2014; RAIFUR; SOUZA, 2016; AGOSTINI; NOSELLA; FILIPPINI, 2017). 


\section{CAPITAL INTELECTUAL}

O conceito de $\mathrm{Cl}$ vem sendo discutido há anos, sendo seus principais precursores Edvinsson e Malone (1998), Stewart (1998) e Sveiby (1998). Esse ativo intangível pode ser entendido como um capital não financeiro que representa a lacuna oculta entre o valor de mercado e o valor contábil das organizações (EDVINSSON; MALONE, 1998). O Cl, na visão de Sharabati,J awad e Bontis (2010), representa a riqueza de ideias e a habilidade de inovar, que determinarão o futuro de uma organização, principalmente por influenciar significativamente no desempenho financeiro das mesmas. A seguir, são detalhados os elementos formadores do $\mathrm{Cl}$.

\subsection{Capital Humano}

Segundo Edvinsson e Malone (1998), os colaboradores que integram a empresa lhe agregam valor, pela sua competência, habilidade e experiência profissional, contudo, para que isto ocorra deve haver 0 aprimoramento constante destes profissionais. Esses conhecimentos, habilidades e experiências profissionais compõem o Capital Humano $(\mathrm{CH})$ da organização.

Para Ciprian et al. (2012, p. 707), "o capital humano é o valor total das habilidades da equipe e se concentra competências (conhecimentos, habilidades, talentos e conhecimentos), atitude (comportamento, satisfação, motivação, desempenho e ética) e a agilidade intelectual (adaptação)". O CH pode ser entendido como a capacidade do funcionário de agir em diversas situações para criar tanto ativos tangíveis como intangíveis (SVEIBY, 1998).

O capital humano é admirável, porque é fonte de inovação e renovação (STEWART, 1998) e sua importância é destacada no contexto das PMEs, devido ao desempenho desses negócios ser explicado pela experiência ocupacional, o nível de treinamento e histórico familiar (RAIFUR; SOUZA, 2016), mas para alavancálo, são necessários ativos intelectuais estruturais (CE), que são os sistemas, laboratórios, entre outros, que suportam toda a operação da empresa.

\subsection{Capital Estrutural}

O Capital Estrutural (CE) estimula e apoia o CH com sua infraestrutura e pode ser dividido em três grupos: o Capital Organizacional, que representa os investimentos em sistemas, instrumentos e filosofia operacional que a empresa faz, para obter competência sistematizada, o Capital de Inovação que é a capacidade de renovação e obtenção de resultados da inovação, propriedade intelectual e outros talentos intangíveis que são direitos comerciais amparados pela Lei e o Capital de Processos que representa os programas técnicos que direcionam os colaboradores a ampliar sua eficiência na produção (EDVINSSON; MALONE, 1998).

Para Macagnan (2009), o CE pode ser dividido em tecnológico e organizativo. 0 tecnológico envolve os investimentos em pesquisa e desenvolvimento, licenças e patentes e a evolução técnica do sistema produtivo, além dos Business Intelligence (FRAGA,et al., 2017). Já o capital estrutural organizativo envolve "indicadores representativos de valores relacionados ao sistema de gestão e toda a atividade técnica e organizativa" (MACAGNAN, 2009, p. 52).

\subsection{Capital Relacional}

Segundo Stewart (1998), o Capital Relacional (CR) é o mais precioso dos ativos intangíveis da organização, pois diz respeito ao relacionamento sucessivo com as pessoas e empresas para as quais vende seus produtos e serviços. O CR está relacionado com a capacidade de interação com o mercado, incluindo todas as relações que a organização estabelece, com clientes, consumidores, intermediários, fornecedores, sócios, donos e credores (Macagnan, 2009). 
Segundo Sveiby (1998, p. 212), "todo o tempo que os funcionários passam trabalhando para os clientes é um tempo potencialmente destinado a manter, estabelecer e desenvolver relações com os clientes". Stewart (1998) defende que o capital do cliente é muito semelhante ao capital humano, pois não é possível possuir os clientes ou pessoas, mas é possível investir no capital intelectual de propriedade conjunta entre os clientes e a empresa. As empresas para atingir suas metas estão cada vez mais investindo no CR e adotando recursos corporativos e ferramentas tecnológicas para manter seus clientes satiffeitos no longo prazo (EDVINSSON; MALONE, 1998).

\section{PROCEDIMENTOS METODOLÓGICOS}

Visando identificar os elementos formadores do capital intelectual no contexto das PMEs, optou-se por realizar um estudo multicaso em duas empresas, denominadas por Empresa Alfa e Empresa Beta, da área comercial, atuantes no ramo de materiais de construção, localizadas no sul do Estado do Mato Grosso do Sul, no centro-oeste brasileiro. As características e informações gerais das empresas participantes foram coletadas por meio de entrevista presencial semiestruturada, realizada entre os dias 21/06/2017 e 30/06/2017, na sede da empresa Alfa e Beta, apresentadas a seguir.

\subsection{Caracterização do Objeto de Estudo}

A empresa Alfa teve sua fundação em 1999, ou seja, atua no ramo de materiais de construção há 17 anos. Possui atualmente um quadro de 13 colaboradores e quatro sócios, dos quais, dois são os sóciosgerentes que administram a empresa de modo geral e tomam decisões estratégicas e rotineiras, tais como, compra e venda de materiais, contratação de funcionários, pequenos investimentos, entre outros. A empresa é classificada como de Pequeno Porte, de acordo com a classificação do SEBRAE, e está organizada como uma sociedade por quotas de responsabilidade limitada e, atualmente está enquadrada no regime tributário do Lucro Presumido. Sua contabilidade é feita totalmente por um escritório terceirizado, que não disponibiliza consultorias externas para melhorar a gestão do negócio.

A empresa Beta foi fundada em 1989, ou seja, atua no ramo do comércio varejista de materiais de construção há 28 anos. A empresa foi constituída por dois sócios, em forma de sociedade por quotas de responsabilidade limitada, sendo adotado o Lucro Real como regime tributário, sua contabilidade é feita por profissionais terceirizados e permanece com esse mesmo quadro social até os dias de hoje. Atualmente, a empresa possui um quadro com 54 colaboradores sendo assim reconhecida como ME (média empresa), de acordo com a classificação do SEBRAE, sendo que esses colaboradores respondem diretamente para um gerente que a ele compete tratar de assuntos administrativos e comerciais. Há também um gerente que é responsável pela área de Recursos Humanos e pelo setor Financeiro.

\subsection{Técnicas de Coleta e Análise de Dados}

A técnica de coleta de dados adotada nesse estudo é a do questionário, adaptado de Bontis (1998). Esse questionário foi aplicado no Canadá por Bontis (1998), na Malásia por Bontis, Keow e Richardson (2000), na J ordânia por Sharabati, J awad e Bontis (2010) e no Brasil por Santos et al. (2016) e Gimenes et al. (2016).

O questionário utilizado contém 56 questões: sendo 19, para identificar a presença de capital humano; 14 , visando identificar a presença de capital de clientes/relacional; 13, para identificar a presença de capital estrutural; e as 10 questões finais investigam qual é a percepção dos participantes quanto à importância da identificação dos elementos formadores do capital intelectual. No questionário utiliza-se a escala de Likert de cinco pontos que é a mais comum em questionários, por representar respostas alternativas por meio de uma escala de percep ção, como demonstrado a seguir: (1) discordo totalmente; (2) discordo parcialmente; (3) não discordo, nem concordo; (4) concordo parcialmente e (5) concordo totalmente. 0 questionário foi aplicado em Setembro de 2017 a dois gestores da empresa Alfa e quatro gestores da empresa Beta, na sede das empresas. 
A identificação da presença dos elementos formadores do $\mathrm{Cl}$ foi realizada através das medidas de tendência central de cada elemento. Para tanto, os dados foram análisados quantitativamente, utilizando a estatística descritiva, por meio do software Stata versão 13.0. A partir da medida de tendência central, foi realizada a classificação de cada elemento formador quanto ao nível de presença do $\mathrm{Cl}$, com base no estudo de Gimenes et al. (2016), que através da análise estatística estabeleceram intervalos de valor e os respectivos níveis de presença do $\mathrm{Cl}$. Os intervalos de valor e os níveis de presença de $\mathrm{Cl}$ utilizados neste estudo são apresentados no Quadro 1.

Quadro 1 - Intervalos de valor e níveis de presença de $\mathrm{Cl}$

\begin{tabular}{|l|l|}
\hline Intervalo de valor & Nível de presença de capital intelectual \\
\hline Inferior a 2,43 & Fraca \\
\hline Entre 2,44 e 3,92 & Média \\
\hline Superior a 3,92 & Forte \\
\hline
\end{tabular}

Fonte: Gimenes et al. (2016, p. 5).

Além do questionário foram realizadas entrevistas presenciais, na sede das empresas no mês de setembro de 2017, com a finalidade de identificar as percepções dos gestores quanto ao $\mathrm{Cl}$. Os dados das entrevistas foram analisados através da análise de conteúdo qualitativa.

\section{RESULTADOS E DISCUSSÃO}

Os resultados do estudo são apresentados em quatro subseções: Capital Humano, Capital Estrutural, Capital Relacional e suas evidências para as empresas Alfa e Beta, bem como a Percepção dos Gestores sobre o $\mathrm{Cl}$.

\subsection{Capital Humano (CH)}

O conhecimento, habilidades e experiências profissionais compõem o $\mathrm{CH}$ da organização. A presença dessa dimensão do Capital Intelectual nas empresas foi identificada utilizando a média das respostas por empresa, apresentadas na Tabela 1.

Tabela 1 - Presença do Capital Humano nas empresas Alfa e Beta

(Continua)

\begin{tabular}{clcc}
\hline Cód. & \multicolumn{1}{c}{ Questões } & $\begin{array}{c}\text { Média da } \\
\text { Empresa } \\
\text { Alfa }\end{array}$ & $\begin{array}{c}\text { Média da } \\
\text { Empresa Beta }\end{array}$ \\
\hline Q1 & $\begin{array}{l}\text { As competências dos colaboradores, como um todo, estão em um } \\
\text { nível considerado ideal. }\end{array}$ & 4,50 & 4,00 \\
Q2 & $\begin{array}{l}\text { Quando um colaborador deixa a empresa, dispomos de um } \\
\text { programa de treinamento e formação para assegurar a sua } \\
\text { substituição. }\end{array}$ & 2,00 & 4,00 \\
Q3 & $\begin{array}{l}\text { Normalmente as tarefas são realizadas dentro dos prazos } \\
\text { estabelecidos. }\end{array}$ & 4,50 & 4,00 \\
Q4 & $\begin{array}{l}\text { A empresa consegue extrair o máximo rendimento dos } \\
\text { colaboradores quando estes trabalham em equipe. }\end{array}$ & 4,50 & 4,25 \\
Q5 & $\begin{array}{l}\text { A empresa promove o desenvolvimento e a manutenção de } \\
\text { relaçõesinternas entre várias equipes de trabalho. }\end{array}$ & 3,50 & 4,50 \\
Q6 & $\begin{array}{l}\text { A organização é bastante inovadora, originando constantemente } \\
\text { novas ideias. }\end{array}$ & 4,50 & 4,75
\end{tabular}


Tabela 1 - Presença do Capital Humano nas empresas Alfa e Beta

(conclusão)

\begin{tabular}{|c|c|c|c|}
\hline Cód. & Questões & $\begin{array}{l}\text { Média da } \\
\text { Empresa Alfa }\end{array}$ & $\begin{array}{c}\text { Média da } \\
\text { Empresa } \\
\text { Beta }\end{array}$ \\
\hline Q7 & $\begin{array}{l}\text { A empresa apoia o colaborador no seu constante desenvolvimento } \\
\text { profissional, realizando ações de formação periódica. }\end{array}$ & 4,50 & 4,00 \\
\hline Q8 & $\begin{array}{l}\text { Os colaboradores da empresa são considerados inteligentes e } \\
\text { criativos. }\end{array}$ & 4,50 & 4,25 \\
\hline Q9 & $\begin{array}{l}\text { Os colaboradores são considerados os melhores do setor em uma } \\
\text { perspectiva regional. }\end{array}$ & 4,00 & 4,00 \\
\hline Q10 & Os colaboradores estão satisfeitos com a empresa. & 4,50 & 4,50 \\
\hline Q11 & $\begin{array}{l}\text { Os colaboradores desempenham as suas tarefas ao máximo das } \\
\text { suas capacidades, de forma completamente satisfatória. }\end{array}$ & 5,00 & 4,00 \\
\hline Q12 & $\begin{array}{l}\text { O nosso processo de recrutamento é muito seletivo. Estamos } \\
\text { direcionados para contratar os melhores candidatos disponíveis. }\end{array}$ & 4,00 & 4,75 \\
\hline Q13 & $\begin{array}{l}\text { Se determinados colaboradores, subitamente, deixassem a } \\
\text { empresa, estaríamos em grandes problemas. }\end{array}$ & 1,50 & 3,00 \\
\hline Q14 & $\begin{array}{l}\text { Os colaboradores geralmente desempenham as suas tarefas com } \\
\text { grande empenho. }\end{array}$ & 4,50 & 4,25 \\
\hline Q15 & $\begin{array}{l}\text { Os colaboradores vão aprendendo uns com os outros, existindo um } \\
\text { elevado nível de troca de informação e conhecimento entre eles. }\end{array}$ & 5,00 & 4,50 \\
\hline Q16 & $\begin{array}{l}\text { Os colaboradores estão empenhados a levarem as suas ideias a } \\
\text { reuniões e a grupos de discussão. }\end{array}$ & 4,00 & 3,75 \\
\hline Q17 & $\begin{array}{l}\text { O fato de os colaboradores desempenharem as suas tarefas no } \\
\text { máximo das suas capacidades, diferencia a nossa empresa das } \\
\text { outras empresas do setor. }\end{array}$ & 5,00 & 5,00 \\
\hline Q18 & $\begin{array}{l}\text { Com a saída de um colaborador da equipe de trabalho, poder-se-á } \\
\text { perder algum valor no capital humano da empresa. }\end{array}$ & 3,50 & 3,50 \\
\hline \multirow[t]{2}{*}{ Q19 } & $\begin{array}{l}\text { O desenvolvimento das pessoas agrega valor a empresa de forma } \\
\text { significativa. }\end{array}$ & 4,50 & 4,75 \\
\hline & Média Total & 4,11 & 4,20 \\
\hline
\end{tabular}

Fonte: Elaborado pelos autores (2018).

Observa-se que, na visão dos gestores, as competências dos colaboradores de ambas as empresas estão em um nível alto. Esse fato fica evidente ao considerar a visão do respondente Gestor B que afirma que "Nem todos estão em um nível ideal, mas uma boa parte da equipe está em um nível bom" corroborando com Edvinsson e Malone (1998), que entendem que os colaboradores que integram a empresa Ihe agregam valor, pela sua competência, habilidade e experiência profissional.

É sabido que sessões de treinamento podem impactar positivamente na empresa se o conhecimento adquirido for disseminado (YANG, 2004). Entretanto, fica evidente que a empresa Alfa não dispõe de um programa de treinamento, segundo o respondente Gestor B da empresa Alfa "o funcionário já ingressa com a mão na massa", diferenciando-se da empresa Beta que considera importante o treinamento dos colaboradores, conforme verificado na resposta do Gestor A que afirma "sem dúvida nós vamos preparar o funcionário. Nós vamos formar este funcionário".

Ao analisar as médias da Questão 3, pode-se inferir que as empresas analisadas possuem prazos para execução de suas tarefas e que as mesmas respeitam estes prazos, sugerindo que, por executarem o que foi planejado, alcancem um bom resultado. Na Questão 17, também é perceptível que as empresas acreditam que por obter o máximo desempenho na execução das tarefas, se tornam as melhores no mercado. Tal crença é demonstrada na resposta do Gestor A da empresa Beta "a gente é o destaque no nosso ramo, na região, por estas funções, pois oferecemos um atendimento que hoje é tudo na empresa".

É evidente que ambas as empresas consideram importante 0 trabalho em equipe, 0 que possibilita um rendimento maior por parte dos colaboradores e maior troca de informações. A importância da capacidade 
coletiva da empresa defendida por Bontis (1998) fica demonstrada na afirmação do respondente Gestor A da empresa Beta "Só funciona bem quando não falha nenhuma engrenagem, eu acho que tem que ser a equipe completa para funcionar cem por cento". É notável que as empresas prezam pelo desenvolvimento das relações entre equipes de trabalho, o respondente Gestor B da empresa Beta compartilhou uma de suas experiências, "Promovi reuniões entre vendedores e crediário, porque um sempre era viláo do outro, o crediário acreditava que 0 vendedor não fazia sua parte, 0 vendedor queria que 0 crediário acelerasse 0 processo sem se preocupar com a qualidade da venda. 0 que a gente foi fazendo, foi melhorar 0 relacionamento, conseguindo assim um bom resultado, através de um diálogo melhor".

Ao observar as médias da Questão 6 e 16 para ambas as empresas, verifica-se que os respondentes enxergam a empresa como promotora de inovação e implantação de novas ideias, sendo estas consideradas como Capital Intelectual por Edvinsson e Sullivan (1996). Um dos canais de comunicação e captação dessas novas ideias dentro da empresa é o gestor da área, isso fica evidente na fala do Gestor B da empresa Beta "por exemplo, o responsável pelo setor do depósito pega ideias da equipe e passa para administração, para possível implantação da mesma", demonstrando a presença do elemento Capital Humano nas empresas de materiais de construção.

A capacitação e os programas de treinamento representam alguns dos fatores relevantes para a geração de capital intelectual proposto por Brooking (1996). Na Questão 07 é possível notar que os colabores estão sendo treinados e desenvolvidos. O Gestor A da empresa Alfa reitera essa evidência ao afirmar que "sempre trazemos palestrantes para dar formação. É importante, para que eles sempre estejam descobrindo novidades, a respeito de como atender e como agir". Isso fica evidente também na Questão 19 onde as empresas acreditam que o desenvolvimento das pesso as agrega valor ao negócio.

As empresas consideram que possuem uma equipe de colaboradores com alto nível de criatividade, que atendem de modo geral as expectativas e necessidades do negócio, sendo esta uma das características do Capital Humano defendidas por Edvinsson e Malone (1998). Verificou-se também que ambas as empresas consideram que possuem os melhores colaboradores em seu quadro de pessoal, profissionais altamente qualificados para atender ao mercado, demonstrando que as empresas estudadas possuem os ativos intangíveis mencionados por Sveiby (1998). Nesse sentido, verificou-se na Questão 14 que tanto a empresa Alfa como a Beta, possuem um nível alto de satisfação com o desempenho de seus colaboradores, entretanto - Gestor B da empresa Beta ressalva que "os colabores têm muito ainda para progredir".

Há uma diferença perceptível entre as duas empresas sobre a substituição de colaboradores, pois a empresa Alfa considera que o colaborador não é insubstituível, conforme alegação do respondente Gestor A "se um funcionário sair há uma lista muito grande de outros que querem trabalhar, e demoraria só um tempo para outro contratado aprender". Já a empresa Beta acredita que se tem uma perda muito grande com a saída de um funcionário. Para o Gestor A "Sem dúvida, dependendo do setor de trabalho do funcionário teremos grandes problemas, pois levará um tempo para treinar outra pessoa". Na Questão 18 pode-se observar que ambas as empresas acreditam que com a saída de um colaborador da empresa perde-se o valor do Capital Humano.

$\mathrm{Na}$ Questão 15 observa-se que em ambas as empresas existem uma alta troca de informações entre os colaboradores, sendo este um dos canais que permeiam a empresa como um todo transferindo o conhecimento adquirido pelos colaboradores ao longo do tempo. Nahapiet e Ghoshal (1998) afirmam que o capital intelectual não é propriedade de um indivíduo, mas é resultado das relações humanas com enfoque nos processos de troca de conhecimento ao longo do tempo.

De modo geral, verificou-se, por meio da medida de tendência central $(4,11$ e 4,20$)$, uma forte presença do $\mathrm{CH}$ tanto na empresa Alfa quanto na empresa Beta, demonstrando que esse elemento está presente no contexto das PMEs estudadas. 


\subsection{Capital Relacional (CR)}

O CR está vinculado a capacidade de interação da empresa com o mercado e todas as relações estabelecidas com os clientes, fornecedores, colaboradores, investidores e credores (MACAGNAN, 2009). Sob esse enfoque teórico, buscou-se identificar a presença do capital relacional nas empresas em estudo, conforme apresentado na Tabela 2.

Tabela 2 - Presença do Capital Relacional nas empresas Alfa e Beta

\begin{tabular}{|c|c|c|c|}
\hline Cód. & Questões & $\begin{array}{c}\text { Média } \\
\text { Empresa } \\
\text { Alfa } \\
\end{array}$ & $\begin{array}{c}\text { Média } \\
\text { Empresa } \\
\text { Beta }\end{array}$ \\
\hline Q20 & $\begin{array}{l}\text { Uma pesquisa com os clientes indicaria que eles, genericamente, estão } \\
\text { satisfeitos com a nossa empresa. }\end{array}$ & 4,50 & 4,25 \\
\hline Q21 & $\begin{array}{l}\text { A empresa tem conseguido reduzir significativamente o tempo de } \\
\text { resolução das reclamações/problemas dos clientes. }\end{array}$ & 5,00 & 4,75 \\
\hline Q22 & $\begin{array}{l}\text { A nossa participação de mercado tem aumentado significativamente } \\
\text { nos últimos anos. A nossa quota de mercado é das mais altas do setor. }\end{array}$ & 4,00 & 4,75 \\
\hline Q23 & $\begin{array}{l}\text { A longevidade de relacionamento que mantemos com os nossos } \\
\text { clientes é admirada/invejada pelos nossos concorrentes. }\end{array}$ & 4,50 & 4,50 \\
\hline Q24 & $\begin{array}{l}\text { Os nossos clientes são leais, mais do que a qualquer outra empresa do } \\
\text { setor. }\end{array}$ & 3,50 & 3,50 \\
\hline Q25 & $\begin{array}{l}\text { A nossa organização orgulha-se de ser totalmente orientada para o } \\
\text { mercado. }\end{array}$ & 4,50 & 4,50 \\
\hline Q26 & $\begin{array}{l}\text { Reunimo-nos periodicamente com os clientes para investigar o que eles } \\
\text { esperam de nós. A informação recolhida do feedback dos clientes é } \\
\text { simultaneamente disseminada pela empresa. }\end{array}$ & 2,50 & 4,00 \\
\hline Q27 & $\begin{array}{l}\text { A maior parte dos colaboradores compreende o nosso mercado alvo e } \\
\text { perfil dos nossos clientes. }\end{array}$ & 4,50 & 4,75 \\
\hline Q28 & $\begin{array}{l}\text { Geralmente nos preocupamos com o que os nossos clientes pensam ou } \\
\text { esperam de nós. }\end{array}$ & 5,00 & 4,50 \\
\hline Q29 & $\begin{array}{l}\text { Investimos nos nossos clientes através da busca contínua de satisfação } \\
\text { das suas necessidades. }\end{array}$ & 4,50 & 4,75 \\
\hline Q30 & $\begin{array}{l}\text { Estamos confiantes, de que, no futuro, os clientes irão manter o seu } \\
\text { relacionamento comercial conosco. }\end{array}$ & 5,00 & 4,75 \\
\hline Q31 & $\begin{array}{l}\text { Dentro das nossas possibilidades, conseguimos extrair o máximo de } \\
\text { feedback dos nossos clientes. }\end{array}$ & 4,00 & 4,75 \\
\hline Q32 & $\begin{array}{l}\text { A "marca" da empresa é bastante reconhecida e respeitada pelo } \\
\text { mercado. }\end{array}$ & 5,00 & 5,00 \\
\hline \multirow[t]{2}{*}{ Q33 } & $\begin{array}{l}\text { A relação com os fornecedores e parceiros comerciais é de confiança e } \\
\text { de comprometimento. }\end{array}$ & 5,00 & 4,75 \\
\hline & Média Total & 4,39 & 4,54 \\
\hline
\end{tabular}

Baseando-se no quadro 3, segue abaixo uma análise comparativa entre as respostas dos gestores da Empresa Alfa e Empresa Beta que evidencia o nível de presença do CR nas organizações. Observa-se que na visão geral dos gestores de ambas as empresas o grau de satisfação dos clientes e time para resolução de problemas é alto, sugerindo a presença do CR no contexto das PMEs em estudo. A presença do CRé importante para potencializar o $\mathrm{Cl}$, conforme destacado por Edvinsson e Malone (1998), ao afirmarem que se for proporcionado ao consumidor satisfação total, ele desejará sucesso total à empresa.

Dada à característica regional e o tempo de atuação das empresas, verificou-se que apesar de diferenças no porte, tanto para a Empresa Alfa quanto para a Empresa Beta, a participação no mercado local tem aumentado significativamente com o passar dos anos. Segundo o Gestor B da Empresa Beta "a soma dos nossos concorrentes representa cinquenta por cento dos nossos clientes". A orientação para o mercado é 
motivo de orgulho para as duas empresas. Isso foi evidenciado pela média de 4,5 para ambas na questão 25 , sendo essa visão classificada como um elemento forte na presença do CR.

Edvinsson e Malone (1998) defendem que o capital relacional é estruturado através do relacionamento da organização com seus clientes e parceiros. Para os respondentes das duas organizações, a relação que cada empresa obtém com seus clientes ao longo dos anos, desde a sua constituição é forte (média $4,5)$ e admirada pelos concorrentes, a fidelidade entre a empresa e seus consumidores agrega valor à empresa, sendo essa uma das principais dimensões do $\mathrm{Cl}$.

O CR decorre das interações entre indivíduos e das redes de relacionamento, sendo a lealdade dos clientes um importante indicador de presença do Cl. Nesse aspecto, as empresas analisadas estão em um nível médio. Segundo o Gestor B da Empresa Beta "no varejo, a cada cinco anos o conceito do cliente muda totalmente, sendo necessário inovar", ou seja, para que exista lealdade entre o cliente e a empresa, a inovação é necessária. É forte o grau de confiança, tanto na Empresa Alfa como na Empresa Beta, de que no futuro os clientes irão manter o relacionamento comercial com as empresas, este quesito é reforçado através da percepção dos entrevistados nas respostas das questões no 20 e $n \div 23$.

Para os gestores da Empresa Alfa, este contato e troca de informações para obter as perspectivas de seus clientes está classificado como nível médio. Já para os gestores da Empresa Beta este feedback ocorre, mas não como o esperado, segundo o Gestor B "Sempre que possível, percorro o chão de loja para ouvir os clientes".

$\mathrm{Na}$ questão 27 evidenciou-se que as duas empresas consideram forte e satisfatório o grau de identificação do mercado-alvo e perfil dos clientes pela maioria dos colaboradores. Já na questão 28 , observase que é forte o grau de preocupação com o que os clientes pensam e esperam da empresa de modo geral. Fica evidente na questão no 23 que as empresas prezam pelo bom relacionamento com seus clientes e investem para satisfazer as necessidades dos clientes, conforme relatado pelo Gestor A da Empresa Beta "o atendimento ao cliente é o nosso maior objetivo".

Segundo Edvinsson e Malone (1998), a marca e as patentes fazem parte do $\mathrm{Cl}$. Verificou-se que a marca, na opinião dos gestores das empresas em estudo, é um elemento forte, pois ambas são reconhecidas e respeitadas pelo mercado regional.

Stewart (1998) defende que o CR representa a estrutura de relacionamento da organização, com a qual a empresa realiza negócios com fornecedores e clientes. Verifica-se que a relação com os fornecedores e parceiros comerciais é outro elemento considerado forte entre os respondentes de ambas as empresas, demonstrando que para os gestores é de suma importância uma boa relação com fornecedores e seus parceiros.

De modo geral, verificou-se que com as médias de 4,39 na Empresa Alfa e 4,54 na Empresa Beta, que ambas têm uma forte presença do $C R$, sendo este um resultado importante principalmente por serem empresas de pequeno e médio porte.

\subsection{Capital Estrutural (CE)}

O CE é representado pelos investimentos em pesquisa e desenvolvimento, licenças e patentes e a evolução técnica do sistema produtivo, envolve ainda os sistemas de gestão e toda a atividade técnica e organizativa (MACAGNAN, 2009). Para identificar a presença do CE no contexto das PMEs, foram feitas as perguntas de 34 a 46 . Os resultados são apresentados na Tabela 3. 
Tabela 3 - Presença do Capital Estrutural nas empresas Alfa e Beta

\begin{tabular}{|c|c|c|c|}
\hline Cód. & Questões & $\begin{array}{c}\text { Média } \\
\text { Empresa } \\
\text { Alfa } \\
\end{array}$ & $\begin{array}{c}\text { Média } \\
\text { Empresa } \\
\text { Beta }\end{array}$ \\
\hline Q34 & A margem de lucro por colaborador tem crescido nos últimos anos. & 4,50 & 3,00 \\
\hline Q35 & $\begin{array}{l}\text { O tempo de realização de uma operação completa (processo produtivo) } \\
\text { tem diminuído ao longo dos últimos anos. }\end{array}$ & 4,50 & 4,75 \\
\hline Q36 & $\begin{array}{l}0 \text { tempo utilizado na realização de uma operação completa é um dos } \\
\text { melhores do setor. }\end{array}$ & 4,00 & 4,50 \\
\hline Q37 & $\begin{array}{l}\text { Grande parte das boas novas ideias geradas na empresa são } \\
\text { implementadas. }\end{array}$ & 4,50 & 4,25 \\
\hline Q38 & $\begin{array}{l}\text { A nossa empresa aposta/investe no desenvolvimento de novas ideias, } \\
\text { produtos e processos. }\end{array}$ & 4,00 & 4,75 \\
\hline Q39 & $\begin{array}{l}\text { A empresa desenvolve mais novas ideias, produtos e processos do que } \\
\text { qualquer outra empresa no setor, em uma perspectiva local. }\end{array}$ & 3,00 & 4,75 \\
\hline Q40 & A empresa orgulha-se da sua eficiência nos últimos anos. & 5,00 & 4,50 \\
\hline Q41 & $\begin{array}{l}0 \text { nosso sistema de informação torna fácil o acesso à informações } \\
\text { relevantes e úteis para a tomada de decisão. }\end{array}$ & 4,50 & 5,00 \\
\hline Q42 & $\begin{array}{l}\text { Os sistemas e processos dentro da organização apoiam e promovem a } \\
\text { inovação. }\end{array}$ & 4,00 & 4,75 \\
\hline Q43 & $\begin{array}{l}\text { A organização é flexível em seus processos internos e possui o mínimo } \\
\text { de burocracia possível. }\end{array}$ & 3,50 & 4,25 \\
\hline Q44 & $\begin{array}{l}\text { A cultura organizacional é flexível, compreensiva e está focada no bem- } \\
\text { estar das pessoas. }\end{array}$ & 4,50 & 4,50 \\
\hline Q45 & $\begin{array}{l}\text { A estrutura organizacional impede que os colaboradores fiquem muito } \\
\text { isolados uns dos outros. }\end{array}$ & 4,50 & 4,75 \\
\hline \multirow[t]{2}{*}{ Q46 } & $\begin{array}{l}\text { Na organização existe partilha de conhecimento entre pessoas e entre } \\
\text { setores internos. }\end{array}$ & 3,00 & 4,50 \\
\hline & Média Total & 4,12 & 4,48 \\
\hline
\end{tabular}

Fonte: Elaborado pelos autores (2018).

A questão sobre o crescimento na margem de lucro por colaborador nos últimos anos, demonstra situações distintas entre as empresas estudadas, pois uma está no nível alto e outra no nível médio. Na Empresa Alfa, a margem de lucro por colaborador tem crescido nos últimos anos, já para a Empresa Beta isto não tem ocorrido com o passar do tempo, sendo confirmado pelo respondente Gestor A ao afirmar que "não cresceu em nada, vem acontecendo o contrário, tivemos uma queda bem drástica".

Pela média $(4,5$ e 4,75$)$ das respostas obtidas, fica evidente a satisfação dos respondentes nas duas empresas, no que diz respeito ao tempo de realização de uma operação completa, ficando claro que todo este processo tem sido realizado em um menor tempo. 0 Gestor B da Empresa Alfa cita exemplo de fatos que aconteceram anteriormente, em situações corriqueiras da empresa, que deixam claro a evolução e rapidez no processo de trabalho na organização, "antigamente o representante comercial vinha com um talão de pedido, e ao pedir cada item o representante conferia com sua tabela, e para comprar cinquenta itens demorava cerca de três horas". Avanços tecnológicos também contribuíram na rapidez dos processos, conforme relatado pelo Gestor B da empresa Alfa "o representante comercial colocava os pedidos na pasta, e transmitia os pedidos por telefone quando chegava na sua casa no final de semana, passando código por código e depois disso demorava mais vinte dias para chegar a mercadoria na loja". O respondente esclarece ainda como ocorre este processo atualmente "Hoje em dia envio um e-mail, em seguida já recebo a cópia do pedido, o vendedor já envia para a fábrica e no outro dia já recebo a Nota Fiscal e já está sendo enviada a mercadoria". Esta evolução fica evidente também pela ótica do respondente na logística para receber seus produtos "Um processo que levava de trinta a quarenta dias por aí, hoje em dez dias a mercadoria já está na loja". Na questão relativa ao orgulho de sua eficiência, verifica-se que os respondentes estão satisfeitos com a eficiência das empresas nos últimos anos. 
Nas duas organizações grande parte das ideias geradas são implementadas, refletindo um bom relacionamento e que as ideias e inovações são aproveitadas pela empresa. Para Antunes e Martins (2002) a aplicação do conhecimento da equipe agrega valores à organização, representando parte do seu $\mathrm{Cl}$. $\mathrm{Na}$ questão sobre criação de novas ideias, produtos e processos, é evidenciada a diferença da Empresa Alfa para a Beta, sendo média na primeira e forte na segunda no desenvolvimento de novas ideias, produtos e processos comparados aos seus concorrentes locais.

A tecnologia conquistou um papel estratégico e vital para as empresas, sendo os investimentos nesses intangíveis uma das vertentes do Capital Intelectual. Quanto ao acesso à informações relevantes e úteis para a tomada de decisão, os gestores percebem uma forte presença do CE em ambas as empresas. De acordo com o Gestor B da Empresa Alfa "a implantação de sistemas melhorou significativamente, sistemas mostram detalhadamente quantos sacos de cimentos eu gastei, antes daria para saber, só que manualmente, de repente levaria um dia para saber". A opinião dos gestores refletem a importância desses sistemas "antigamente eu fazia uma planilha, ia no estoque físico e contava um por um, depois somava tudo, e hoje com o estoque controlado, eu puxo o relatório de inventário e já tenho todo meu estoque, portanto a tecnologia ajudou muito" segue afirmando o Gestor B da Empresa Alfa. Observa-se que, tanto na Empresa Alfa como na Empresa Beta, os gestores acreditam que os sistemas e processos internos apoiam e promovem a inovação dentro de suas organizações.

Para Edvinsson e Malone (1998), o CE estimula e apoia o Capital Humano com sua infraestrutura. Na Empresa Alfa, observa-se que a organização da empresa, a flexibilidade dos processos internos e a burocracia nas suas operações estão em um nível médio, ou seja, não está como o desejado pelos gestores. Para os respondentes da Empresa Beta fica evidente que a empresa tem buscado organizar e flexibilizar seus processos, conforme afirmação do Gestor B "somos flexíveis, a burocracia que temos aqui é a necessária, nada além disso".

Nas duas organizações pode-se constatar que a cultura organizacional é flexível, de modo satisfatório para seus gestores, sendo compreensiva e focada no bem-estar de seus colaboradores, fornecedores e clientes. A estrutura organizacional na Empresa Alfa, como na Empresa Beta, impede que os colaboradores fiquem muito isolados uns dos outros, resultando assim em uma melhor comunicação entre os colaboradores e seus setores.

A partilha de conhecimento entre pessoas e entre setores internos é classificada como média na Empresa Alfa, ou seja, não deixa de existir essas interações entre a equipe, mas não ocorre como o desejado pelos respondentes. Já para a Empresa Beta, na visão geral dos gestores esse índice é forte, entretanto, segundo o Gestor B "concordo parcialmente, não há tanto como deveria, temos que evoluir muito".

\subsection{Percepções sobre o Capital Intelectual}

Verifica-se que as empresas consideram que o $\mathrm{Cl}$ agrega valor ao novo modelo de gestão. Segundo o Gestor B da empresa Beta, "No meu ponto de vista o Capital Intelectual é importantíssimo sim. Mas dentro da empresa devemos dar mais espaço pra isso, a gente ainda precisa evoluir bastante, tem que se dar mais importância do que esta se dando".

Mesmo reconhecendo a importância do $\mathrm{Cl}$, as empresas Alfa e Beta não possuem nenhuma medida de avaliação de desempenho não financeiro. Sobre o $\mathrm{Cl}$, o Gestor A da empresa Alfa afirma que "eu concordo que se deve ter, mas hoje nós não temos isso". Para o Gestor B da empresa Beta essa informação é útil "por exemplo para dar função, cargos melhores, deixar que cresçam quem tá aqui dentro, sem ter que trazer de fora, é vantajoso". E mesmo ambas as empresas não possuindo nenhum tipo de medida de avaliação de desenvolvimento não financeiro, elas acreditam que é necessário levá-las em consideração na tomada de decisão.

Observou-se que ambas afirmam que a empresa possui um valor maior do que o registrado contabilmente. Para o respondente Gestor B, "a marca tem mais valor do que o próprio capital", demonstrando que o respondente reconhece a presença do Capital Intelectual na realidade local. Conforme questão 53 , as empresas reconhecem que o Capital Intelectual aumenta o valor da empresa, portanto, não a venderiam por 
seu valor contábil. Na visão do Gestor B, da empresa Beta, "São várias situações. Você venderia os 28 anos de credibilidade, você vende ponto, você venderia várias coisas além do valor contábil, vende a marca".

Com relação à tecnologia na gestão financeira do negócio, se é considerado muito mais rápido e fácil o acesso às demonstrações financeiras, pois "Trimestralmente o próprio escritório faz todo um balanço patrimonial para nós, ativos, passivos, capital, então assim além de você puxar no sistema muita informação, o próprio contábil hoje pelo remoto que fico ligado puxa todas as informações, então é muito mais rápido". Sobre o $\mathrm{CH}$, ambas as empresas concordam que o êxito alcançado está diretamente ligado ao seu Capital Humano.

\subsection{Síntese das evidências da presença do Capital Intelectual no contexto das PMEs}

Após a análise de cada elemento formador do $\mathrm{Cl}$, foi calculado a média por empresa para enquadramento definitivo da presença dos elementos na empresa. Segue Tabela 5 com o ponto de tendência central detalhado por elemento e por empresa.

Tabela 5 - Evidências da presença do Capital Intelectual por empresa

\begin{tabular}{lll}
\hline Elemento & Alfa & Beta \\
\hline Capital Humano & 4,11 & 4,20 \\
Capital Relacional & 4,39 & 4,54 \\
Capital Estrutural & 4,12 & 4,48 \\
\hline Média & $\mathbf{4 , 2 1}$ & $\mathbf{4 , 4 1}$ \\
\hline
\end{tabular}

Fonte: Elaborado pelos autores (2018).

A forte presença dos elementos formadores do $\mathrm{Cl}$ no contexto das PMEs ficou demonstrado na Tabela 5 utilizando como base os intervalos de valor e níveis de presença de $\mathrm{Cl}$ propostos por Santos et al. (2016). A Figura 1demonstra a síntese das evidências, permitindo uma visão global dos resultados obtidos em cada elemento formador do $\mathrm{Cl}$ por empresa.

A empresa Beta enquadrada como média empresa, apresentou maiores evidências da presença dos elementos formadores do $\mathrm{Cl}$, se comparada à empresa Alfa, enquadrada como pequena empresa. Observa-se no Gráfico 1, que as variáveis $\mathrm{CH} 2$, CH5, CH13, CR26, CR31, CE34, CE39, CE 43 e CE46 apresentaram maiores diferenças entre as empresas Beta e Alfa. Verifica-se que to dos os elementos formadores do $\mathrm{Cl}$ apresentaram fortes níveis de presença, ressalta-se que o elemento mais presente no contexto das PMEs analisadas é o CR, que caracteriza as relações pessoais entre colaboradores, clientes e fornecedores e o elemento com menor intensidade foi o $\mathrm{CH}$. 
Figura 1 - Comparação analítica dos elementos formadores do Capital Intelectual

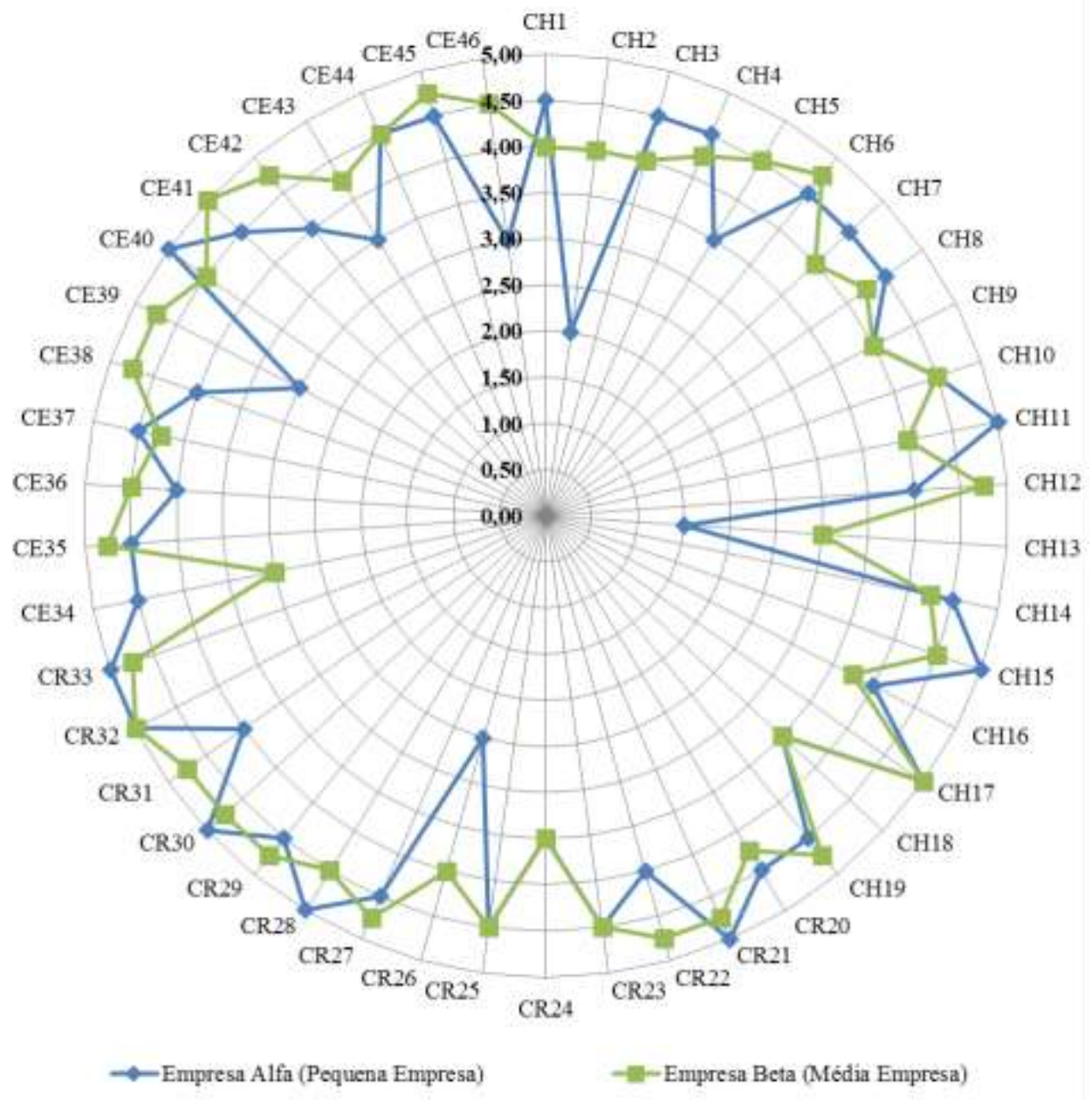

Fonte: Elaborado pelos autores (2018).

\section{CONCLUSÕES}

A principal contribuição deste estudo reside na identificação de uma forte presença dos elementos $\mathrm{CR}, \mathrm{CE}$ e $\mathrm{CH}$, tanto na empresa Alfa (pequena empresa) quanto na empresa Beta (média empresa), demonstrando que esses elementos do $\mathrm{Cl}$ estão presentes no contexto das PMEs. Tais achados contribuem para que sejam desenvolvidas futuras pesquisas sobre o Capital Intelectual considerando as particularidades dos pequenos negócios no Brasil.

As evidências de conteúdo permitem inferir que os gestores das PMEs sabem da existência do $\mathrm{Cl}$, que acreditam na sua importância e também na importância da identificação de seus elementos, porém ainda não possuem medidas que possibilitam mensurar esses ativos intangíveis. Verificou-se o desejo dos gestores de obterem relatórios que evidenciem o grau de contribuição dos elementos formadores do $\mathrm{Cl}$ no aumento do valor da empresa, possibilitando uma tomada de decisão acurada, principalmente quanto aos investimentos.

Como limitações do estudo, têm se a utilização de multicasos de pequenas e médias empresas do estado do Mato Grosso do Sul, não retratando o vasto universo das PMEs brasileiras e a utilização de respostas da alta gestão das empresas, visto que qualquer aplicação de questionário e/ou entrevista está sujeita ao viés do respondente, o que impossibilita a generalização dos resultados.

Devido ao acirramento da concorrência, escassez de recursos e dinamismo do mercado torna-se necessário investir em áreas que potencializam o aumento do $\mathrm{Cl}$ com enfoque na agregação de valor e vantagem competitiva. Nesse sentido, sugere-se que sejam realizados estudo futuros com um maior número 
de empresas, preferencialmente de outros segmentos e portes, para comparação com os resultados aqui apresentados. Sugere-se também que sejam realizados estudos que desenvolvam relatórios de mensuração do $\mathrm{Cl}$, com enfoque na criação de valor por elemento, visando atender a demanda dos stakeholders.

\section{REFERÊNCIAS}

AGOSTINI, L.; NOSELLA, A.; FILIPPINI, R. Does intellectual capital allow improving innovation performance? A quantitative analysis in the SME context. J ournal of Intellectual Capital, Dundee, v. 18, n. 2, p. 400-418, 2017.

ANTUNES, M. T. P. A Controladoria e o Capital Intelectual: um estudo empírico sobre sua gestão. Revista Contabilidade \& Finanças - USP, São Paulo, v. 17, n. 41, p. 21-37, 2006.

ANTUNES, M. T.P.; MARTINS, E. Capital Intelectual - Verdades e Mitos, Revista de Contabilidade e Finanças - USP, São Paulo, v. 13, n. 29, p. 41-54, 2002.

BONTIS, N. Intellectual capital: an exploratory study that develops measures and models. Management Decision, Guildford, v. 36, n. 2, p. 63-76, 1998.

BONTIS, N.; KEOW, W. C.; RICHARDSON, S. Intellectual capital and business performance in Malaysian industries. Journal of Intellectual Capital, Dundee, v. 1, n. 1, p. 85-100, 2000.

BONTISA, N.; et al., The knowledge to olbox: a review of the tools available to measure and manage intangible resources. European Management Journal, Glasgow, v. 17, n. 14, p. 391- 402, 1999.

BROOKING, A. Intellectual capital: core assets for the third millennium enterprise. Stamford: Thomson Business Press, 1996.

CARLOS FILHO et al. Importância e contribuição do ativo intangível: percepção dos empreendedores de micro e pequenas empresas so bre o capital intelectual. Revista Organizações em Contexto, São Paulo, v. 10, n. 20, p. 1-27, 2014.

CIPRIAN, G. G. et al. Elaboration of accounting financial report on structural capital. Procedia - Social and Behavioral Sciences, Londres, v. 62, n. 24, p. 706-710, 2012.

COLAUTO, R. D. et al. Avaliação do capital intelectual desenvolvido em organizações não governamentais: comparação entre entidades brasileiras e portuguesas. Enfoque: Reflexão Contábil, Maringá, v. 30, n. 2, p. 923, 2011.

CRUZ, J. C. S.; ALVES, M. T. V. D. Capital Intelectual: práticas de divulgação de informação em empresas portuguesas. Revista Universo Contábil, Blumenau, v. 9, n. 2, p. 174-194, 2013.

DORCE, L. C.; CAVALHEIRO, R. T.; GIMENES, R. M. T. Capital Intelectual: uma análise bibliométrica da produção científica brasileira. Revista FSA, Teresina, v. 14, n. 3, p. 28-54, 2017.

EDVINSSON, L.; MALONE, M. S. Capital intelectual: descobrindo o valor real de sua empresa pela identificação e seus valores internos. São Paulo: Makron Books, 1998.

EDVINSSON, L.; SULLIVAN, P. Developing a model for managing intellectual capital. European Management Journal, Glasgow, v. 14, n. 4, p. 356-364, 1996.

ENSSLIN, S. R. et al. Uma Metodologia Multicritério (MCDA-C) para apoiar o gerenciamento do capital intelectual organizacional. RAM - Revista de Administração Mackenzie, São Paulo, v. 9, n. 7, p. 136-162, 2008. 
FRAGA, B. D. et al. Business Intelligence: métodos e técnicas de gestão do conhecimento e as tendências para avanços do capital intelectual. Navus - Revista de Gestão e Tecnologia, Florianópolis, v. 7, n. 1, p. 43-56, 2017.

GIMENES, R. M. T. et al. Capital Intelectual em Organizações Hospitalares. In: CONGRESSO BRASILEIRO DE CONTABILIDADE, 20., 2016, Fortaleza. Anais... Fortaleza: CBC, 2016, p. 1-14.

GUBIANI, J. S.; MORALES, A. B. T.; SELIG, P. M. A Influência do Capital Intelectual no Potencial de Inovação das Universidades. Iberoamerican Journal of Industrial Engineering, Florianópolis, v. 5, n. 9, p. 01-22, 2013.

JOIA, L. A. Medindo o Capital Intelectual. Revista de Administração de Empresas - RAE, São Paulo, v. 41, n. 2, p. 54-63, 2001.

MACAGNAN, C. B. Evidenciação voluntária: fatores explicativos da extensão da informação so bre recursos intangíveis. Revista Contabilidade \& Finanças - USP, São Paulo, v. 20, n. 50, p. 46-61, 2009.

NAHAPIET, J.; GHOSHAL, S. Social Capital, Intellectual Capital, and the organizational advantage. Academy of Management Review, Nova lorque, v. 23, n. 2, p. 242-266, 1998.

OLIVEIRA, J. M.; BEUREN, I. M. O tratamento contábil do capital intelectual em empresas com valor de mercado superior ao valor contábil. Revista Contabilidade \& Finanças - USP, São Paulo, v. 14, n. 32, p. 81$98,2003$.

RAIFUR, L.; SOUZA, A. F. Impactos do Capital Humano no Desempenho de Pequenas e Médias Empresas. Revista da Micro e Pequena Empresa (FACCAMP), Campo Limpo Paulista, v. 10, n. 3, p. 33-48, 2016.

REIS, L. G. As dificuldades de mensuração e consequente divulgação nas demonstrações contábeis do Capital Intelectual: uma reflexão teórica. Contabilidade Vista \& Revista, Belo Horizonte, v. 16, n. 2, p. 43-60, 2005.

ROOS, G.; ROOS, J. Measuring your company's Intellectual performance. Long Range Planning, St. Gallen, v. 30, n. 3, p. 413-426, 1997.

SANG, H. K.; DENNIS, T. Intellectual capital vs the book-value of assets: A value-relevance comparison based on productivity measures. Journal of Intellectual Capital, Dundee, v. 15, n. 1, p. 65-82, 2014.

SANTOS, T. G. S. et al. Capital intelectual em organizações hospitalares: um estudo de caso do hospital santa casa de Maringá. Revista Espacios, Caracas, v. 37, n. 36, p. 1-15, 2016.

SHARABATI, A. A. A.; JAWAD, S. N.; BONTIS, N. Intellectual capital and business performance in the pharmaceutical sector of Jordan. Management Decision, Guildford, v. 48, n.1, p. 105-131, 2010.

SILVA, C. D. F.; NAGANO, M. S.; MERLO, E. M. Gestão do capital de relacionamento: estudo de caso em uma tradicional fábrica no Brasil. Revista de Administração Mackenzie - RAM, São Paulo, v. 9, n. 6, p. 53-76, 2008.

STEWART. T. A. Capital Intelectual: a nova vantagem competitiva das empresas. Rio de Janeiro: Campus, 1998.

SVEIBY, K. E. A nova riqueza das organizações: gerenciando e avaliando patrimônios do conhecimento. Rio de Janeiro: Campus, 1998.

VARGAS, V. C. C. et al. Avaliação dos intangíveis: uma aplicação em capital humano, Gestão \& Produção, São Carlos, v. 15, n. 3, p. 619-634, 2008.

YANG, J. Qualitative Knowledge capturing and organizational learning: two case studies in Taiwan hotel. Tourism Management, Hamilton, v. 25, n. 4, p. 421-428, 2004. 